\title{
DEMOCRACIA Y DOS SENTIDOS DE LIBERTAD*
}

\author{
Lucas Sierra \\ Centro de Estudios Públicos
}

\begin{abstract}
RESUMEN: Frente a la pregunta que indaga las relaciones entre conceptos amplios como democracia y libertad, esta conferencia propone focalizarse en la democracia entendida como mecanismo procedimental (una forma de tomar decisiones políticas), por una parte, y la libertad entendida a la luz de los dos conceptos de libertad de Isaiah Berlin (positiva y negativa), por la otra. La democracia permite que cada individuo participe de la limitación de su propia libertad, dando así cabida al concepto de libertad positiva. Se trataría, en otras palabras, de una forma colectiva de autolimitación. Hay libertad negativa, en cambio, cuando no existe interferencia en la esfera individual. Podría ser factible que existiera libertad negativa sin democracia y libertad positiva sin democracia, aunque es más probable que ambas florezcan en democracia. La negativa explica mejor las realidades contemporáneas, su fuerza radica en que no se pregunta por "ontologías" ni menos intenta fijarlas para dar sentido a la colectividad. Por lo mismo, el autor echa de menos en los debates actuales la referencia a este concepto de libertad tan primordial.

Palabras Clave: democracia, libertad negativa, libertad positiva, Isaiah Berlin.
\end{abstract}

Lucas Sierra. Abogado, Universidad de Chile. LL.M. Universidad de Yale. Ph.D. Universidad de Cambridge. Profesor de Derecho de las Telecomunicaciones, Universidad de Chile. Investigador del Centro de Estudios Públicos (CEP). Email: 1sierra@cepchile.cl.

* Transcripción de la presentación hecha el 27 de octubre de 2011 en la sesión "Libertad y democracia” del ciclo para estudiantes universitarios “¿Cuánta libertad?”, organizado por el CEP. Véase en esta misma edición la conferencia de Juan Pablo Mañalich. 


\section{DEMOCRACY AND TWO MEANINGS OF LIBERTY}

ABSTRACT: In order to answer the question of the relationship between concepts as democracy and liberty that can be defined in so many different ways, this conference proposes focusing, on the one hand, on an understanding of democracy as a procedural mechanism (a way of adopting political decisions), and on the other, on an understanding of liberty in light of the two meanings of liberty according to Isaiah Berlin (positive and negative). Democracy allows each individual to participate in the limitation of his own liberty, thus making room for the positive meaning of liberty. Democracy would be then a collective form of selflimitation. On the other hand, negative liberty exists when there is no interference in the individual sphere. It might be feasible for both negative and positive liberty to exist without democracy, but it is more likely that both will flourish within democracy. Negative liberty, however, best explains the contemporary reality, its force not coming from an "ontology" or any attempt to establish one in order to give meaning to the collectivity. For the same reason, the author misses the reference to such a fundamental concept of liberty in current debate.

KEYwords: Democracy, negative liberty, positive liberty, Isaiah Berlin.

A veces pareciera que la experiencia no sirve para nada. Cuando hace ya varios meses, Ernesto Rodríguez y Francisco Arellano me propusieron participar en una conversación sobre la libertad que se realizaría a fines — en ese entonces — de un muy lejano mes de octubre, dije, desaprensivamente, que sí.

Cuando ya la guadaña del plazo se acercaba, me di cuenta del problema en que me había metido (y, quizás, del error que habría cometido): la conversación iba a ser sobre libertad y democracia. Desde el punto de vista de la reflexión política, de moralidad política, es difícil encontrar dos conceptos más generales, más gaseosos. Me empecé a acordar con nostalgia y algo de culpa, de mi supervisor en Cambridge, quien, con buen criterio, me repetía, como un mantra, cada vez que nos veíamos: "focus".

¿Cómo fijar un "focus" en dos extensiones tan grandes como democracia y libertad? ¿Cómo poder echarse a nado en semejante océano semántico, sin ahogarse a las pocas brazadas? 
En lo que sigue ensayaré una forma de hacerlo, una muy básica. Partiré de una base más o menos obvia: aunque relacionados entre sí, los conceptos de libertad y de democracia son distintos. En algún sentido se superponen, pero hay otros importantes en los que no.

Libertad y democracia, entonces, no son sinónimos. La democracia parece superponerse con la libertad cuando ésta se piensa en sentido "positivo", pero pensada en un sentido "negativo", la libertad se distancia y puede llegar a contraponerse a la democracia. Propongo, en consecuencia, que pensemos no en democracia y libertad, sino que en democracia y dos sentidos de libertad. Antes de ir a esto, sin embargo, un par de palabras sobre la idea de democracia que subyace en este texto.

Es una idea de democracia bastante mínima, de un carácter más bien procesal: un mecanismo para la toma de las decisiones políticas en una sociedad. Un mecanismo que, bajo de condiciones de universalidad e igualdad, agrega y procesa preferencias. Esas condiciones se logran contabilizando un voto por persona (de aquí la importancia de la regla de mayoría), intentando que dicho voto sea lo más informado posible, e intentando, también, que las elecciones sean correctas y periódicas. Además, este proceso para la toma de decisiones que es la democracia, no es mecánico. Por el contrario, la democracia debe configurarse como un espacio institucional para la deliberación pública, que permita que las preferencias no sólo se expresen, sino que, además, puedan moldearse a la luz de la deliberación colectiva. En síntesis, para el sentido mínimo de democracia que contiene este texto, además del input y del output, importa también, y mucho, el proceso.

En cambio, el concepto de libertad que aquí se usa, no es para nada mínimo. Tiene un sentido doble, complejo, tal como se describe en el intuitivo y profundo ensayo de Isaiah Berlin sobre los dos sentidos en que se puede entender la libertad: como libertad "positiva" y como libertad "negativa"1.

La libertad positiva puede ser representada por la pregunta sobre lo que determina que una persona sea o haga algo de una manera y no de otra. Se trata de una pregunta por el control del propio yo, por la fuente de este control, dicho más precisamente. Es una libertad de soberanía. 1969).

${ }^{1}$ Isaiah Berlin, Four Essays on Liberty (Oxford: Oxford University Press, 
La libertad negativa, en cambio, puede ser representada por la pregunta sobre el ámbito o la esfera en que una persona es dejada libre para que pueda ser o hacer algo, sin que terceros interfieran con ella. Es una libertad de no interferencia.

Tras hacer esta distinción, Berlin plantea que, si bien son dos preguntas distintas, las respuestas a ellas pueden coincidir.

Esta distinción entre democracia y dos sentidos de libertad, y la idea de que la democracia está más cerca de la idea de libertad positiva y más lejos de la negativa, tienen que ver, me parece, con algunas tipologías conceptuales usadas por la teoría de la moral y el derecho:

- La distinción entre utilitarismo y deontología.

- La distinción, como tan bien la desarrolla Rawls, entre justificar una regla y justificar un acto que cae bajo dicha regla ${ }^{2}$.

- Entre el carácter agregativo de una decisión y el carácter individualizado de otra.

- $\quad$ Entre política y derecho(s).

- $\quad$ Entre la idea del bien y la de idea de lo correcto, como horizontes justificatorios del orden político y social.

Vuelvo a los dos conceptos de libertad. Esta tarde sostendré que la democracia es más inmediatamente cercana a la libertad "positiva" y que, por lo mismo, ambos conceptos (democracia y libertad "positiva") se asemejan y, de alguna manera, se superponen. Pero también sostendré que éste no es el caso de la libertad "negativa". Empíricamente, la libertad negativa suele florecer en democracia más que en ningún otro régimen político, pero, teóricamente, la democracia puede asfixiarla.

La distinción entre estos dos conceptos o sentidos de la libertad se hizo famosa con el discurso que pronunció Berlin al asumir, hace más de 50 años, la cátedra Chichele sobre teoría social y política en Oxford. En el discurso hizo mucho hincapié en el hecho de que se trataba de teoría "política" y llamó a considerar las implicancias políticas que pueden tener las ideas con que teorizamos. En otras palabras, me parece, él nos llama a pensar en el contexto del poder político. En los tiempos modernos, esto significa estar siempre conscientes de que la presencia del Estado y sus poderes son potencialmente enormes.

2 John Rawls, "Two Concepts of Rules", The Philosophical Review 64 (1955): 3-32, disponible en: http://www.dif.unige.it/dot/filosofiaXXI/rawls.pdf. 
Asimismo, junto con trazar la distinción entre los dos conceptos de libertad mencionados, Berlin también advirtió sobre la pretensión de algunos pensadores, y de algunas doctrinas, de que los distintos fines que podemos perseguir en la vida no serían potencialmente antagónicos entre sí, como parecen serlo, sino que podrían convivir armónicamente en una especie de paraíso sistémico, en medio de una total coherencia interna. Esto, en razón de que dichos fines de la vida podrían ser reducidos, finalmente, a un principio simple o a un puñado de creencias básicas. Desde el punto de vista de la teoría política, Berlin nos precave: esta pretensión no sólo es infundada, sino también peligrosa.

Berlin sintetizó el punto de vista político de su reflexión mediante estas preguntas que apuntan al núcleo de la moral política: ¿Por qué debo yo, o cualquier otra persona, obedecer a alguien? ¿Por qué yo no habría de vivir como yo quiero? ¿Debo obedecer? ¿Y si no obedezco, podría ser objeto de coacción? ¿Quién podría ejercer esta coacción? ¿Con cuánta intensidad? ¿En nombre de qué y con qué propósito?

Teniendo siempre en cuenta este horizonte político que enfatiza Berlin, propongo entonces que en lugar de pensar en democracia y libertad, pensemos en democracia y dos sentidos de la libertad.

Como decía al principio, la democracia es una forma de tomar decisiones políticas. La democracia permite que estas decisiones sean tomadas por quienes van a experimentar las consecuencias de ellas. De este modo, las personas convertidas en ciudadanos se auto-regulan. La vida en sociedad - en comunidad política - exige imponerse ciertas restricciones recíprocas. Si éstas se imponen mediante los procedimientos de la democracia, cada uno de nosotros puede pensar que no es sólo una imposición ajena, sino que, también, tiene mucho de auto-imposición.

En esto se conecta umbilicalmente la idea positiva de la libertad. Como ya apuntamos, ésta es una libertad de soberanía, de control sobre uno mismo, de autocontrol. El punto es: si cada ciudadano participa - directa o indirectamente - en el dictado de las leyes, aunque estas leyes puedan restringirlo en algún sentido, su libertad positiva queda incólume, pues ha sido en ejercicio de ella, precisamente, que dichas restricciones han sido impuestas, autoimpuestas más bien. Es libertad positiva: un ejercicio de autogobierno.

Un ejercicio de autogobierno que, al realizarse al interior de la comunidad política, es colectivo. Por esto la libertad en su sentido positivo puede 
predicarse con similar igualdad a las personas como individuos o como colectivos. La libertad positiva se manifiesta en el autogobierno de la polis. Es una libertad colectiva, una soberanía del "cuerpo político".

La libertad negativa, en cambio, es mucho más individual. Es muy difícil predicarla de algo así como el "cuerpo" político. Es una libertad, como se dijo, de no interferencia. Una persona tiene libertad negativa en un determinado ámbito de su vida si puede actuar en ese ámbito sin que nada o nadie restrinja su acción. Nada más. Aquí no es relevante que esa persona no pueda (por falta de habilidad, recursos, o de ambas cosas) desarrollar plenamente ese aspecto de su vida, que no pueda, respecto de ella, autogobernarse o tener su pleno control. Lo único que importa es que nadie interfiera con ella.

Puede haber libertad negativa, entonces, sin democracia. No es muy fácil que ocurra en la práctica, pero es algo que podría pasar. Un ejemplo clásico de esto es el hipotético reino de un déspota ilustrado (y liberal) que se perpetúa en el poder, pero que, al mismo tiempo, lo ejerce sin interferir con las esferas individuales de sus súbditos. Un caso poco usual, sin duda, pero plausible.

Es más difícil que en ese reino exista libertad positiva. Ésta, como hemos visto, se pregunta por la fuente real del control o, en otras palabras, por la capacidad de autogobierno. En tal reino ella es una capacidad muy limitada, puesto que el autogobierno político, al menos, está impedido por el déspota.

Pero así como podría haber libertad negativa sin democracia, también podría haber democracia sin libertad negativa. Éste es el objeto de esta presentación.

Cabe considerar aquí la cuestión de la minoría. Si la democracia no está bien reglada y la mayoría puede avasallar, la minoría o las minorías pueden verse excesivamente interferidas, sin libertad negativa.

Como sabemos, la minoría no es un concepto estático, una categoría ontológica. Es un concepto dinámico, pues representa gradientes de poder. Se puede ser, al mismo tiempo, minoría en un aspecto y mayoría en otro.

Berlin nos advierte que ciertas derivaciones más o menos perversas de la libertad positiva permiten pensar que una minoría oprimida puede ser, no obstante, plenamente libre. Por ejemplo, asumiendo una actitud estoica, de retraimiento al yo interior, que resulta así controlado, ya sea en relación con las circunstancias externas (la opresión política, por ejemplo), o con las 
internas (como sus pasiones o necesidades personales). Un yo interior autocontrolado, soberano, como el del esclavo que dominándose a sí mismo se tiene por más libre que su amo; o del prisionero que en la medida que ha podido afianzar su verdadero ser es más soberano, más libre positivamente hablando, que su cancerbero. Interiormente, él y sólo él es su amo.

Más perversa aún es la posibilidad de que la mayoría tenga a la minoría que avasalla como libre, en tanto la está forzando a ajustarse o a ser fiel a lo que la mayoría tiene como el verdadero ser, el verdadero "yo", de esa minoría. Piénsese, por ejemplo, en los campos de adoctrinamiento en la Camboya de Pol Pot, o en las incursiones de Sendero Luminoso en las aldeas de la sierra peruana. El poder político usado para "liberar" a las personas, incluso de su falso yo. Liberarlas de ellas mismas.

Además de ser conceptualmente razonable, en fin, me parece moralmente correcto distinguir democracia y libertad por la vía de separar conceptualmente la libertad negativa, esto es, la libertad de actuar en determinados ámbitos sin interferencia. Vale la pena separarla a fin de poder mantener la democracia, y a la libertad positiva que la subyace, bajo constante examen y escrutinio.

La libertad negativa es un instrumento político relativamente simple: no supone que el poder organizado se tenga que preguntar por ontologías, ni por la verdadera esencia de los seres humanos. Simplemente implica abstenerse y dejar ser; abstenerse y dejar hacer.

Por esto, la libertad en su sentido negativo es altamente compatible con las sociedades extensas y complejas como son las sociedades contemporáneas. Es la libertad de la sociedad y no de la comunidad. Es la libertad de la ciudad y no de la familia.

Hoy, entre nosotros, creo, estas consideraciones parecen estar vivas (aunque a veces algo ocultas) a propósito del debate sobre la igualdad. Es posible advertir en algunos discursos, me parece, una vinculación muy intensa entre igualdad, libertad positiva y democracia, vinculación tras la cual la libertad negativa no asoma por parte alguna.

Ojalá me equivoque. EP 